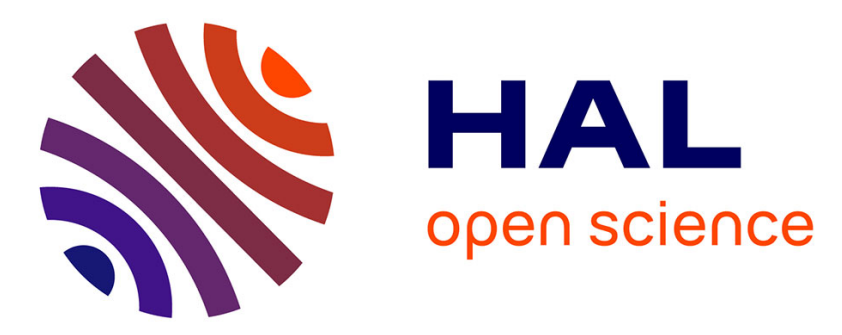

\title{
Spatial frequency and face processing in children with autism and Asperger syndrome
}

Christine Deruelle, Cécilie Rondan, Bruno Gepner, Carole Tardif

\section{To cite this version:}

Christine Deruelle, Cécilie Rondan, Bruno Gepner, Carole Tardif. Spatial frequency and face processing in children with autism and Asperger syndrome. Journal of Autism and Developmental Disorders, 2004, 34, pp.199-210. hal-00250051

\section{HAL Id: hal-00250051 https://hal.science/hal-00250051}

Submitted on 8 Feb 2008

HAL is a multi-disciplinary open access archive for the deposit and dissemination of scientific research documents, whether they are published or not. The documents may come from teaching and research institutions in France or abroad, or from public or private research centers.
L'archive ouverte pluridisciplinaire HAL, est destinée au dépôt et à la diffusion de documents scientifiques de niveau recherche, publiés ou non, émanant des établissements d'enseignement et de recherche français ou étrangers, des laboratoires publics ou privés. 


\title{
Spatial Frequency and Face Processing in Children with Autism and Asperger Syndrome
}

\author{
Christine Deruelle, ${ }^{1,5}$ Cecilie Rondan, ${ }^{1,4}$ Bruno Gepner, ${ }^{2}$ and Carole Tardif ${ }^{3}$
}

\begin{abstract}
Two experiments were designed to investigate possible abnormal face processing strategies in children with autistic spectrum disorders. A group of 11 children with autism was compared to two groups of normally developing children matched on verbal mental age and on chronological age. In the first experiment, participants had to recognize faces on the basis of identity, emotion, gaze direction, gender, and lip reading. All aspects of face processing, except for identity matching, were deficient in the autistic population compared with controls. In the second study, children had to match faces on either high-(i.e., local facial features) or low-spatial frequency information (i.e., global configuration of faces). Contrary to the control subjects, children with autism showed better performance when using high rather than low spatial frequency, confirming face-processing peculiarities in this population.
\end{abstract}

KEY WORDS: Autism; Asperger syndrome; face processing; high and low spatial frequency.

\section{INTRODUCTION}

Although social and communicative deficits are undoubtedly the most striking manifestations characterizing the autistic spectrum disorder (ASD), individuals with autism also present atypical visual processing; for instance, when they perceive faces or geometrical patterns.

Peculiar visuo-spatial skills have often been reported in tasks involving the processing of geometrical figures or objects (e.g., Frith, 1989; Happé, 1999; Shah \& Frith, 1993). People with autism show better abilities than their control subjects when searching for a part embedded in a figure (e.g., Shah \& Frith, 1983)

\footnotetext{
${ }^{1}$ Center of Research in Cognitive Neuroscience, CNRS, Marseille, France.

${ }^{2}$ Child Psychiatry Department, Montperrin Hospital, Aix en Provence, France.

3 "Speech and Language" Laboratory, University of Provence, Aix en Provence, France.

${ }^{4}$ Laboratory of Psychology and Neurocognition, CNRS, UMR 5105, Grenoble, France.

${ }^{5}$ Correspondence should be addressed to Dr. Christine Deruelle, CRNC, CNRS, 31 chemin Joseph Aiguier, 13402 Marseille cedex 20, France; e-mail: chris@1nf.cnrs-mrs.fr
}

and in the block design task (e.g., Shah \& Frith, 1993). Happé (1996) also showed that, in contrast to typically developing children, those with autism did not succomb to visual illusions. These observations, together with anecdotal reports and clinical evidence, have lead several authors to propose that autistic persons focus on details at the expense of global or contextual understanding (e.g., Frith, 1989). According to Frith's (1989) theory of "weak central coherence," autism is characterized by a cognitive style biased toward local rather than global information processing. This means that they tend toward local details (i.e., elements constituting a figure) and have difficulties integrating the details into a coherent whole (i.e., the global configuration of the figure). This preference for local processing stands in sharp contrast with what is found in typically developing adults (e.g., Navon, 1977), children (e.g., Deruelle, Mancini, Livet, Cassé Perrot, \& de Schonen, 1999), and infants (e.g., Frick, Colombo, \& Ryther Allen, 2000). In the normal population, the global aspect of figures is processed before the local aspects. For instance, with hierarchical stimuli (i.e., a large letter made of smaller letters), subjects respond quicker to the large letter than to the smaller letters (e.g., Navon, 1977). 
Performance of autistic subjects also appears at odds with that of the normal population within the domain of face recognition. Langdell (1978) found that young autistic children tend to focus their attention on the lower part of the face, whereas normal control subjects exhibit a bias toward the upper part. Moreover, it appears that, as for object processing, autistic subjects present peculiar ways of processing faces by relying more on local facial features than on configural aspects of faces (i.e., the relationship between the different parts). Performance of adolescents and adults with autism (Hobson, Ouston, \& Lee, 1988) and of autistic children (Langdell, 1978; Tantam, Monaghan, Nicholson, \& Stirling, 1989) was not altered, compared with controls, when faces were presented inverted. In these studies, autistic subjects made an equal number of correct answers when faces were presented upright and inverted, whereas control children made significantly more errors when faces were presented inverted compared with upright. The lack of face-inversion effect is taken as a sign of a local rather than a configural processing of faces because only local information is available in inverted faces (e.g., Carey \& Diamond, 1994). In line with this, data from Miyashita's study (1988) indicated that autistic children recognized schematic face stimuli by relying on the facial features only. The same conclusion was drawn when using photographs of faces (Davies, Bishop, Manstead, \& Tantam, 1994; Hobson et al., 1988; Kracke, 1994). More recently, a study using functional magnetic resonance imaging (fMRI) demonstrated that individuals with autistic spectrum disorders, contrary to normal controls, exhibited a pattern of brain activity during face discrimination that is typical of object perception and consistent with feature-based strategies (Schultz et al., 2000). These latter findings indicate that autistic individuals attend to the local aspects of faces rather than to the whole structure. This preference for the local facial information is in opposition with the configural advantage in face processing found in the normal adult population (Carey \& Diamond, 1977; Rhodes, 1988; Tanaka \& Farah, 1993; Young, Hellawell, \& Hay, 1987) and during childhood (Baenninger, 1994; Carey \& Diamond, 1994; Deruelle \& de Schonen, 1998; Lundy, 2000; Tanaka, Kay, Grinnell, Stansfield, \& Szechter, 1998).

Many authors have examined the relevance of low- and high-spatial frequency information in facerecognition tasks. Visual information is analyzed by a series of channels tuned to different spatial frequency ranges. Spatial frequencies are integrated in a low-to- high processing order, with low spatial frequencies being processed faster than high spatial frequencies (e.g., Breitmeyer, 1984). These findings have been related to the more general proposal that the global aspects of an image are available before the finer details (e.g., Hughes, Nozawa, \& Kitterle, 1996). By extension, it has been established that the configural properties of a face are better represented at a low than at a high spatial frequency level (e.g., Costen, Parker, \& Craw, 1994). Low-pass filtering blurs faces, and this renders the facial features unavailable. In contrast, when faces are high-pass filtered, the contrasts are increased, which renders the facial features highly salient. A greater use of low- than of high-spatial frequency information in face processing has been supported by numerous studies on normal adults (e.g., Fiorentini, Maffei, \& Sandini, 1983; Schyns \& Oliva, 1999; Sergent, 1982, 1986), thus confirming the predominance of configural processing in face recognition (e.g., Tanaka \& Farah, 1993).

To our knowledge, no data are available on the use of high- and low-spatial frequency information in autistic children. Whether face processing relies on high- or on low-spatial frequency information is, however, of particular importance to understand atypical visual processing in the autistic population. In particular, the use of this technique may indicate whether or not the weak central coherence (WCC) hypothesis (i.e., a configural processing impairment) could apply to the domain of face recognition.

This study was aimed at further questioning in which way autistic children process faces differently from controls. More precisely, predictions issued from the WCC theory were assessed in two experiments. In the first experiment, the performance of autistic children was evaluated through a battery of face-matching tasks that differed in their need for local or configural analysis, and their performance was compared to that of control subjects. The second experiment was designed to verify whether the same autistic subjects processed faces differently from controls when manipulating the stimuli in terms of spatial frequencies and, thus, to determine the role of configural versus local analysis in face processing.

\section{EXPERIMENT 1}

Experiment 1 used a sample matching task to evaluate autistic perceptual abilities in five different facerecognition tasks (identity, gaze, gender, emotional 
Table I. Characteristics of Autistic Children

\begin{tabular}{rllccc}
\hline Subjects & Diagnostic & Gender & $\begin{array}{c}\text { Chronological age } \\
(\text { CA })\end{array}$ & $\begin{array}{c}\text { Verbal mental age } \\
\text { (VMA) }\end{array}$ & $\begin{array}{c}\text { Childhood autism rating scale } \\
\text { (CARS) }\end{array}$ \\
\hline 1 & Asperger & Male & 4.5 & 4.6 & 25 \\
2 & Autism & Male & 7.8 & 4.0 & 38 \\
3 & Autism & Male & 7.10 & 6.6 & 36 \\
4 & Asperger & Male & 8.5 & 8.5 & 20 \\
5 & Autism & Male & 8.5 & 4.5 & 38 \\
6 & Autism & Male & 10.0 & 4.6 & 38 \\
7 & Autism & Female & 10.2 & 6.9 & 32 \\
8 & Autism & Female & 10.6 & 6.3 & 36 \\
9 & Asperger & Male & 10.9 & 8.9 & 25 \\
10 & Autism & Female & 11.1 & 17.0 & 38 \\
11 & Asperger & Female & 13.1 & 12.1 & 27 \\
\hline
\end{tabular}

expression, and lip reading). Specific predictions concerning which aspect of face processing should or should not be deficient in children with autism is quite difficult to ascertain from previous studies. This difficulty is the result of large disparities both in the population recruited (severity of autistic syndrome and age of participants may vary among studies) and in the variety of tasks used.

According to the WCC theory, it could be hypothesized that the processing of facial aspects that require configural processing should be more impaired in the autistic population than the processing of those that may be solved based on components or local features. In particular, performance of children with autism should be deficient in the identity, gaze, and emotional expression processing that involves configural analysis (e.g., Calder, Young, Keane, \& Dean, 2000; Ricciardelli, Ro, \& Driver, 2002), whereas their performance should be relatively preserved in gender and lip-reading processing that may be tackled with componential analysis (e.g., Campbell, Landis, \& Regard, 1986; Yamaguchi, Hirukawa, \& Kanazawa, 1995).

Using a simultaneous matching task, Gepner, de Gelder, and de Schonen (1996) demonstrated that whereas the recognition of facial identity, lip reading, and gaze direction discrimination were not impaired in children and adolescents with autism compared with that of their verbal controls, the recognition of emotions was poorer in autistic subjects. Generalization from this study is, however, difficult, as underlined earlier. Experiment 1 thus assesses the reliability of Gepner et al.'s (1996) findings by testing various faceprocessing abilities with a simultaneous matching task in our particular sample of subjects.

\section{Participants}

Three groups of children were tested. The first group included 11 children with autism or Asperger syndrome that we will designate as the autistic group (ASD). All diagnoses were based on the DSM-IV (American Psychiatric Association, 1994) and were made by a child psychiatrist (B.G.) after extensive diagnostic evaluation, including a review of prior records (developmental history and child psychiatric and psychological observations). According to the DSM-IV criteria for autism, seven subjects were diagnosed with autism and four with Asperger syndrome (see Table I). The autistic children were aged between 4 years 6 months and 13 years 1 month (mean $=9$ years 3 , months; SD $=2$ years 3 months). Their developmental verbal age was measured with the TVAP ${ }^{1}$ (Test de Vocabulaire Actif et Passif; Deltour \& Hupkens, 1980) and ranged from 4 years 4 months to 12 years 1 month (mean $=6$ years 7 months, $S D=2$ years 4 months). It was ensured that verbal mental age was sufficient to comprehend the tasks used in this study. The severity of the children's autism or Asperger syndrome was estimated by a child psychiatrist (B.G.) with the CARS score (Childhood Autism Rating Scale; Schopler, Reichler, DeVellis, \& Daly, 1980), which

\footnotetext{
${ }^{1}$ The TVAP is made up of 30 sets of five pictures. These pictures represent either objects or actions. This test is divided into two subtests (Passive and Active Vocabulary subtests). In the Passive Vocabulary subtest, the experimenter asks the child to point to one of the five pictures. This subtest assesses verbal comprehension level. In the Active Vocabulary subtest, the experimenter asks the child to give a definition of one of the five pictures. This subtest assesses verbal expression level. In our study, autistic children were matched with normally developing children, using the Passive Vocabulary subtest only.
} 
ranged from 20 to 38 (mean $=32, \mathrm{SD}=6.6$ ). Five of these children attended a child daycare psychiatric unit for children with developmental disorders (Montperrin Hospital, Aix en Provence), four children attended special educational programs for children with learning disabilities, and two children followed normal schooling. None of them had known associated medical disorders at the time of testing, and visual examination was found to be normal. Five additional participants with autism were recruited for the study but were not included in the final sample because they failed to understand the tasks. However, no statistical comparison between verbal IQs of these subjects and those of the subjects left in the final sample was performed because of too small samples.

The autistic group was matched to two control groups consisting of normally developing children. Children of the first control group (verbal mental age [VMA]) were individually matched on gender and verbal comprehension level $(\mathrm{n}=11$, mean age $=6$ years 6 months, $\mathrm{SD}=2$ years 3 months) to the autistic participants, and children of the second group (chronological age [CA]) were individually matched on gender and chronological age $(\mathrm{n}=11$, mean age $=9$ years 5 months, $\mathrm{SD}=$ 2 years 4 months) to the autistic participants. Parents of both autistic and control subjects consented to the participation of their children in this study.

\section{Tasks and Stimuli}

Stimuli consisted of black-and-white photographs of 25 adult faces and five faces of children wearing scarves to mask their hair. They were of $6 \times 6$ degrees of visual angle viewed at $60 \mathrm{~cm}$ from a portable screen. These photographs of faces were the same as the ones used in Deruelle et al. (1999). All participants underwent five sessions of a face-matching task. There was one session in each of the following five conditions: identity matching across different emotional expressions or across different point of views, matching based on emotional expression (disgust, surprise, happiness), matching based on lip reading ("a" "o" and "i"), matching based on gaze direction (leftward, rightward, and straight forward), and matching based on gender. The target and the comparison faces displayed different individuals in all matching conditions except identity. Gender and age of the face stimuli were counterbalanced across trials.

\section{Procedure}

Participants were individually tested in a quiet room at the child daycare unit in the Montperrin hospital
(Aix en Provence) or at their home. They were seated in front of a portable computer (Macintosh), on which the stimuli were presented. The size of the portable screen was 14 inches. Subjects underwent a twoalternative forced-choice (2AFC) matching task. Three stimuli were simultaneously displayed, one at the top and two at the bottom of the screen. Subjects were asked to indicate by a key-press which one of the two faces displayed at the bottom of the screen was of the same identity, showed the same emotional expression, mouthed the same sound, looked in the same direction, or was of the same gender as the face at the top of the screen. They were to press the "a" keyboard ${ }^{2}$ button when choosing the face on the left side or the "p" button when choosing the face on the right side. These keys were identified by using patches of different colors. Note that the subjects were already familiarized with this task because they had been enrolled in a previous set of experiments involving a similar procedure (Deruelle, Rondan, Gepner, Wicker, \& Fagot, submitted). Each participant underwent a total of 70 trials comprising Identity (15 trials), Emotional Expression (15 trials), Gaze Direction (15 trials), Lip-Reading (15 trials), and Gender (10 trials) conditions. Gender condition contained fewer trials than the other conditions, as there were only two alternatives (male/female). Trials were blocked within each condition, and the order of presentation was counterbalanced across participants.

\section{Results}

An analysis of variance was performed on the percentage of correct responses, with the Group (ASD, VMA, and CA) as the between-subject factor and Condition (Identity, Emotional Expression, Gaze Direction, Gender, and Lip Reading) as the withinsubject factor. The Group effect was significant $[\mathrm{F}(2,30)=19.1, p<.001]$, showing lower performance in the ASD group compared with the VMA group $[\mathrm{F}(1,20)=17.2, p<.001]$ or the CA group $[\mathrm{F}(1,20)=24.6, p<.001]$. The Condition effect was also significant $[\mathrm{F}(4,120)=20.2, p<.001]$, as well as the Group by Condition interaction $[\mathrm{F}(8,120)=5.6$, $p<.001]$.

Further analysis of this interaction revealed group differences in the Emotional Expression, Gaze Direction, Gender, and Lip-Reading conditions [respectively, $\mathrm{F}(2,30)=20.6, p<.001 ; \mathrm{F}(2,30)=20.2, p<.001$; $\mathrm{F}(2,30)=4.6, p<.05 ;$ and $\mathrm{F}(2,30)=6.1, p<.01$; see

\footnotetext{
${ }^{2}$ Note that we used a French keyboard.
} 


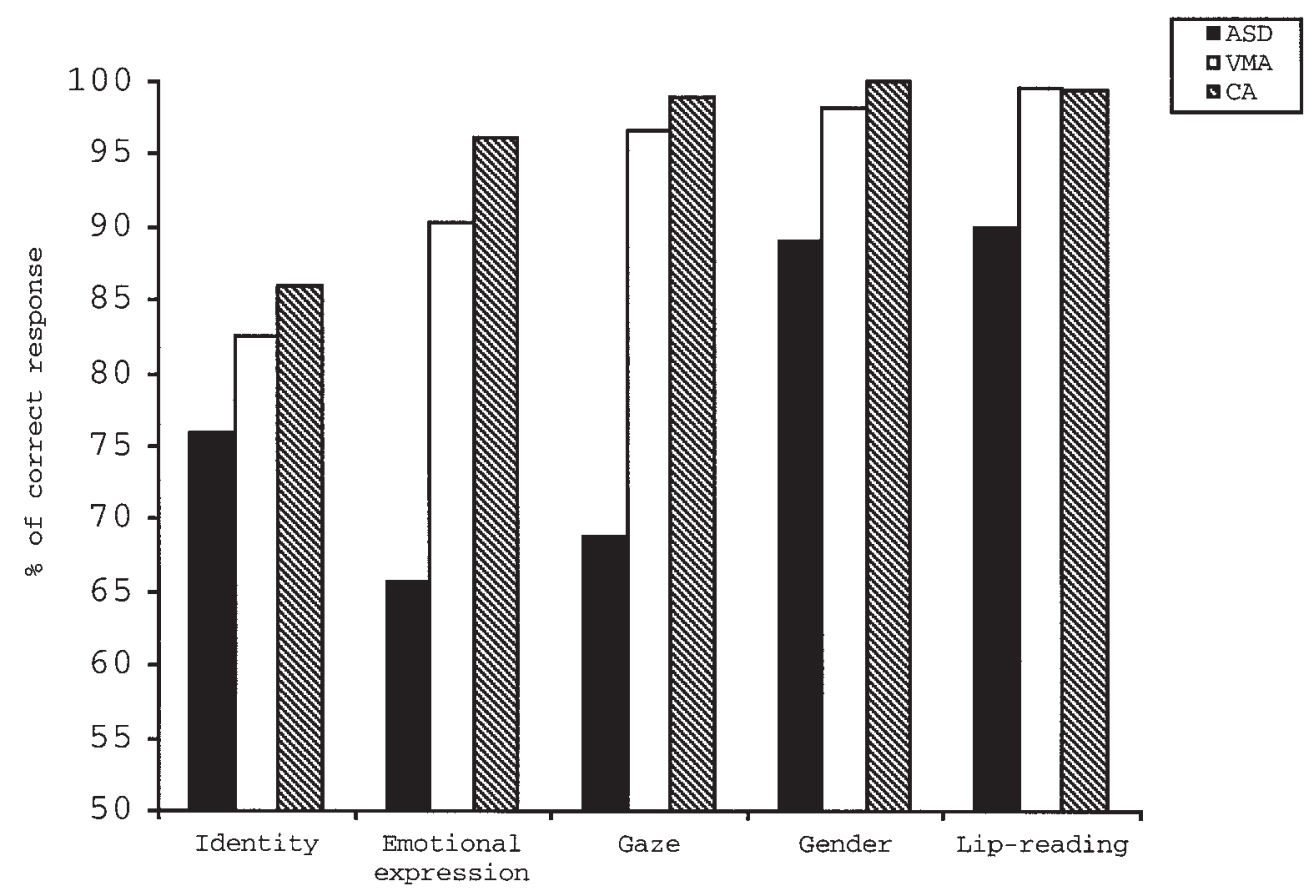

Fig. 1. Mean percentage of correct responses in each of the five face conditions for the three groups of subjects (Autistic Spectrum Disorder, Verbal Mental Age-matched, and Chronological Age-matched).

Fig. 1]. Autistic children performed poorer than the VMA and CA groups in the Emotional Expression, Gaze Direction, Gender, and Lip-Reading conditions. The three groups did not differ when the Identity condition was considered $[\mathrm{F}(2,30)=1.9, p>.10]$. The Condition factor was significant in each experimental group [ASD: $\mathrm{F}(4,40)=11.4, p<.001 ; \mathrm{VMA}: \mathrm{F}(4,40)=$ 10.1, $p<.001$; CA: $\mathrm{F}(4,40)=8.4, p<.001]$.

Within the ASD group, performance in the Identity condition was significantly poorer than in the Gender and the Lip-Reading condition [respectively, $\mathrm{F}(1,10)=$ $6.7, p<.05 ; \mathrm{F}(1,10)=13.3, p<.01)$. Furthermore, performance in Emotional Expression was significantly poorer than in Gender $[\mathrm{F}(1,10)=27.6, p<.001]$ and Lip Reading $[\mathrm{F}(1,10)=59.4, p<.001]$, and the Gaze condition was less well performed than the Gender $[\mathrm{F}(1,10)=10, p<.05]$ and Lip-Reading Conditions $[\mathrm{F}(1,10)=21.8, p<.001$; see Table II $]$. Results in Identity, Gaze, and Emotional Expression conditions did not differ from each other $(p>.05)$.

The VMA group exhibited lower performance in the Identity condition than in all other conditions [Emotional Expression: $\mathrm{F}(1,10)=5.2, p<.05$; Gaze: $\mathrm{F}(1,10)=23.8, p<.001$; Gender: $\mathrm{F}(1,10)=22.2$, $p<.001$; Lip Reading: $\mathrm{F}(1,10)=36.2, p<.001$; see Table II]. Similarly, the CA group performed poorer
Table II. Scores Obtained by the Three Groups in Each Condition of Experiment 1

\begin{tabular}{lccccc}
\hline & \multicolumn{5}{c}{ Face tasks } \\
\cline { 2 - 6 } Group & Id. & Em. & Ga. & Ge. & Li. \\
\hline AUT & & & & & \\
$\quad$ Mean & 76 & 65.7 & 68.9 & 89.1 & 90 \\
SD & 11 & 16.8 & 19.4 & 14.5 & 12.4 \\
Verbal mental age & & & & \\
$\quad$ Mean & 82.6 & 90.3 & 96.6 & 98.2 & 99.5 \\
SD & 9.7 & 10.3 & 8.1 & 6 & 1.8 \\
Chronological age & & & & \\
Mean & 85.9 & 96.1 & 98.9 & 100 & 99.4 \\
SD & 14 & 5.1 & 3.8 & 0 & 2 \\
\hline
\end{tabular}

Note: Id., Identity; Em., Emotional expression; Ga., Gaze; Ge., Gender; Li., Lip-Reading.

in the Identity condition than in all other conditions [Emotional Expression: $\mathrm{F}(1,10)=5, p<.05$; Gaze: $\mathrm{F}(1,10)=14.3, p<.01$; Gender: $\mathrm{F}(1,10)=11.2, p<$ .01 ; Lip Reading: $\mathrm{F}(1,10)=9.2, p<.05$; see Table II]. These findings indicate that Identity matching was not the easiest condition for children with autism, but that it was the most difficult condition for the control groups. 
The effect of age on performance was evaluated by performing the Spearman Rank Correlation test for each matching condition. For the CA group, no significant correlation emerged between chronological age and performance (all $p>.10$ ). For the VMA group, the only aspect of face processing that improved with age was the gender judgment $(\mathrm{Rho}=.63, p<.05)$. In the ASD group, significant correlation was found between performance in the Lip-Reading condition for both verbal mental age $(\mathrm{Rho}=.69, p<.05)$ and chronological age $(\mathrm{Rho}=.62 ; p<.05)$.

\section{Discussion}

We wish to emphasize that Experiment 1 findings showed that autistic subjects displayed more difficulties than control subjects in the majority of the facial tasks. These data bring further evidence to a longlasting debate that face-processing difficulties in autism were not limited to the processing of emotional expressions. Our results showed that several aspects such as gender, lip-reading, and gaze discrimination were also altered in autistic subjects when compared to control subjects, confirming previous reports (BaronCohen, Campbell, Karmiloff-Smith, \& Grant, 1995; de Gelder, Vroomen, \& Van der Heide, 1991; Gepner et al., 1996).

Interestingly, performance of the autistic children was similar to that of the two control groups in the facial identity-matching condition. One may argue that our subject-matching procedure was not sensitive enough to reveal performance differences in the identity condition. Indeed, some authors have proposed that matching by verbal mental age might mask possible deficits, at least in tasks involving emotion processing (e.g., Celani, Battacchi, \& Arcidiacono, 1999). We still think that our procedure is a conservative procedure that minimizes group differences (Fein, Lucci, Braverman, \& Watherhouse, 1992). Moreover, it is very unlikely that this matching procedure could explain a lack of difference between autistic and control subjects in the facial identity but not in the other aspects of face processing that have been tested.

Considering several reports in the literature indicating that autistic children preferentially rely on local rather than on configural facial information (e.g., Hobson et al., 1988; Kracke, 1994; Schultz et al., 2000), it is surprising that facial-identity matching was the only aspect of face processing that was not deficient in our autistic population compared with controls. Indeed, identity matching required the recognition of a face under different emotional expressions and under different viewpoints, and this ability is usually considered to involve configural processing (e.g., Hill, Schyns, \& Akamatsu, 1997). It is possible, however, that control and autistic subjects used different strategies despite a similar level of performance. Even though identity matching usually involves a configural analysis in typically developing children (e.g., Tanaka et al., 1998), one cannot reject the idea that autistic children could resolve the task by relying on facial components only. As both target and comparison figures remained visible until the subject gave his/her answer, an analytical analysis comparing facial features by components was possible.

This explanation is furthermore supported by the relative strength and weakness within the ASD group in the different face tasks. Children with autism present more difficulty in Identity, Gaze, and Emotional Expression matching than in Gender and Lip-Reading matching. It has been established that identity, gaze, and emotional expression requires configural processing (e.g., Calder et al., 2000). In contrast, Gender (e.g., Yamaguchi et al., 1995) and Lip Reading (e.g., Campbell, et al., 1986) rely on the use of a local strategy. Our data are then consistent with a configural processing impairment in the autistic population (e.g., Hobson et al., 1988; Kracke, 1994; Schultz et al., 2000), and thus are consistent with the WCC prediction. This way of analyzing faces differs from what is observed in typically developing children, and our findings indicate the use of different facial processing strategies by autistic and typically developing children. This experience leads us to propose that the WCC in autism would apply not only to the processing of geometrical shapes but also to facial processing. An alternative explanation could be to consider that the aspects of faces that are impaired in the autistic population are deficient not because they rely on configural analysis but because they are involved in communication and social interaction in which autistic persons are weak (DSM IV; American Psychiatric Association, 1994). If this second explanation is valid, it seems that lip reading should also be impaired, as it is implicated in verbal communication. Instead, lip reading is relatively preserved in our population of children with autism as in other studies, at least when static stimuli are used (e.g., Gepner et al., 1996).

As it is difficult to draw conclusions from the results of Experiment 1 about the strategies used by the autistic population in face recognition, the hypothesis of a configural face-processing impairment will be directly assessed in the following experiment. 

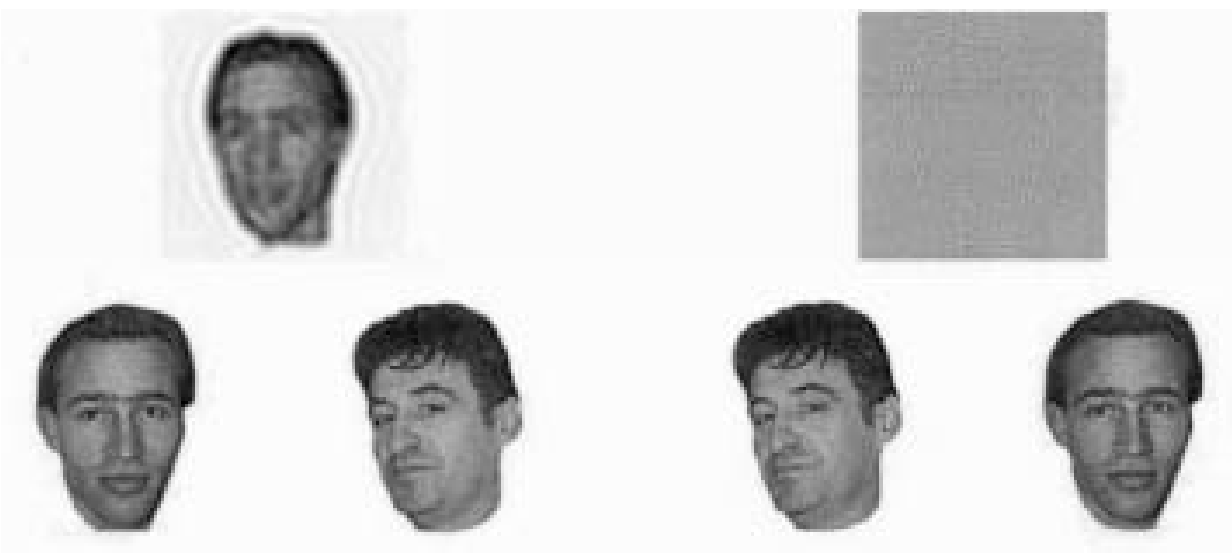

Fig. 2. Example of stimuli used in the high- (right side) and low-pass filtered (left side) condition in experiment 2 .

\section{EXPERIMENT 2}

The previous experiment showed that performance of the autistic subjects did not differ from their control groups in the facial identity task. ${ }^{3}$ The main goal of experiment 2 was to assess whether the strategies used by the autistic children in the facial identity task imply visual processing different from those used by normal controls, despite equivalent performance. This experiment is built on the argument that low-spatial frequency images convey more configural features than local ones, whereas the local features are primarily conveyed by high spatial frequencies (Hughes et al., 1996; Lamb \& Yund, 1993; Shulman \& Wilson, 1987). When applied to face recognition, fine details of facial features (i.e., local cues) are available when the stimulus contains high spatial frequencies but not when it contains only low facial frequencies.

Considering the hypothesis that autistic and Asperger subjects rely more on local than on configural information in face processing, we expected that more errors would be made by autistic children when presented with low-pass compared with high-pass filtered faces. In contrast, as control children are supposed to rely on configural rather than on local processing (e.g.,

\footnotetext{
${ }^{3}$ For reasons of convenience and duration of testing, we used only identity matching under different viewpoints in this second experiment. Preliminary analysis of results from experiment 1 revealed no difference between matching identity under different viewpoints $(\mathrm{M}=78 \%$ correct $)$ compared with matching identity under different emotions ( $\mathrm{M}=76.4 \%$ correct) in the autistic group $(p>.05)$. Moreover, performance of autistic children was different from neither that of $\mathrm{CA}$ (viewpoint $\mathrm{M}=86.6 \%$ correct, emotion $\mathrm{M}=84.1 \%$ correct) nor of VMA (viewpoint $\mathrm{M}=82.3 \%$ correct, emotion $\mathrm{M}=83.4 \%$ correct) controls in either identity condition (all $p>.05$ ).
}

Carey \& Diamond, 1994), they should make more errors in the high-pass than in the low-pass filtered situations.

\section{Participants}

The same subjects as in experiment 1 participated in this experiment. A maximum of 1 month elapsed between the first and the second experiment.

\section{Stimuli}

The stimuli set was composed of black and white $256 \times 256$-pixel photographs depicting four different poses of three male faces. Poses varied from nearly frontal to three-quarter views. Each photograph was low-pass filtered (LSF, below two cycles/degree of visual angle) and high-pass filtered (HSF, above six cycles/degree of visual angle), ${ }^{4}$ so that the stimuli set contained 24 filtered faces. Twelve LSF and $12 \mathrm{HSF}$ faces were used as targets. Only male faces were used because they were easier to homogenize compared with female faces. Each stimulus subtended $6^{\circ} \times 6^{\circ}$ of visual angle when viewed at a distance of $60 \mathrm{~cm}$.

\section{Procedure}

A trial consisted of the simultaneous presentation of three faces on the screen: one target (LSF or HSF face) at the top, and two probes (unfiltered faces) at the bottom left and right of the screen (see Fig. 2). Each target was presented twice so that children underwent a total of 48 trials composed of 24 LSF and 24 HSF trials.

\footnotetext{
${ }^{4}$ These values of low- and high-pass cut-off corresponded to those usually used in adult studies on the role of spatial frequencies in face processing (e.g., Costen, Parker, \& Craw, 1994).
} 


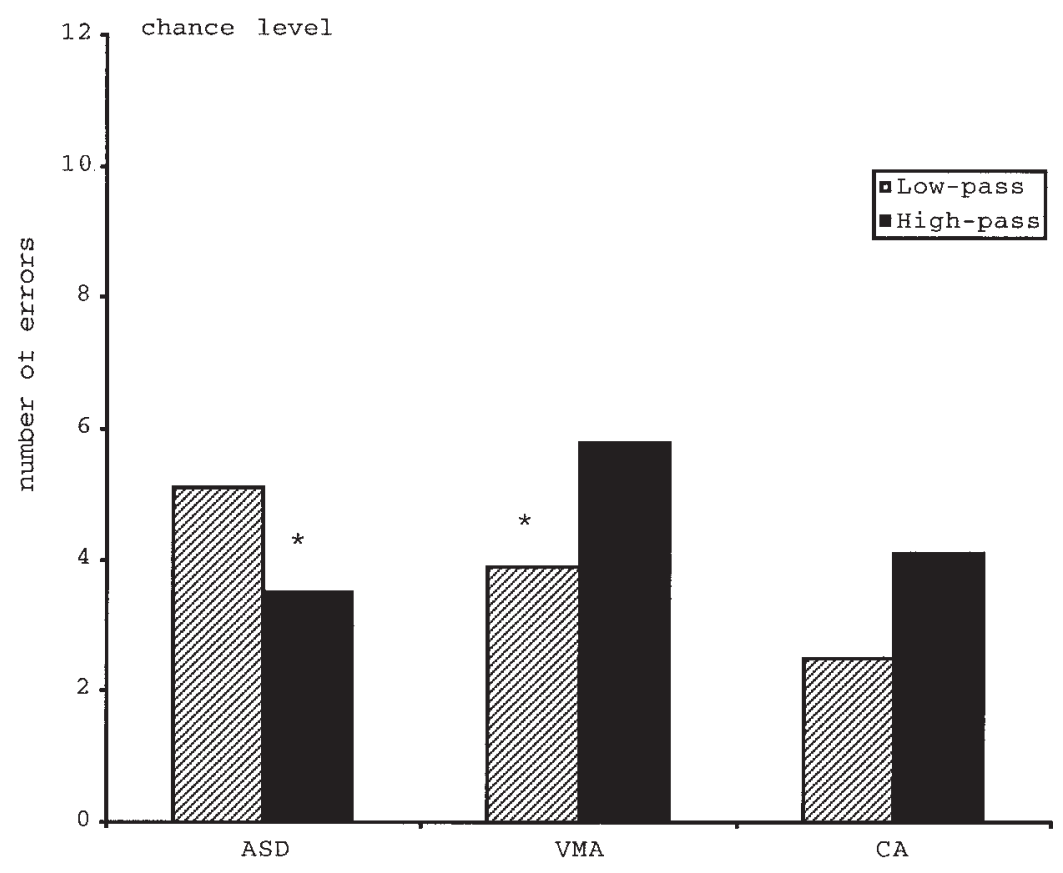

Fig. 3. Mean number of errors in the high- and low-pass filtered conditions of experiment 2 in the three groups of subjects (Autistic Spectrum Disorder, Verbal Mental Agematched, Chronological Age-matched).

The positive probe was the unfiltered version of another viewpoint of the face displayed as the target, and the negative probe was an unfiltered face of another individual matched with the target on hairstyle, skin complexion, and eye color. All the negative probes also served as positive probes in another trial. Position (right or left) of the positive probe was counterbalanced across trials. LSF and HSF trials were mixed within a block, and trial orders were randomized for each subject.

The subjects were tested individually at their home or in a quiet room in the child daycare unit in the Montperrin hospital (Aix en Provence). They were seated in front of a portable computer on which the stimuli were displayed. Subjects were asked to decide whether the face on the bottom left or the bottom right was of the same identity as the LSF or the HSF face presented on the top of the screen. Children had to press the "a" keyboard button if they chose the face on the left side, or the "p" button for the face on the right side. Patches of different colors were used to identify response keys. A few $(n=5)$ training trials with unfiltered face stimuli were given to the subjects before the test to ascertain that they understood the task.

\section{Results and Discussion}

A $3 \times 2$ analysis of variance was performed on the number of errors, with Group (ASD, VMA, CA) as between-subject factor and Condition (LSF/HSF) as within-subject factor. The Group $\times$ Condition interaction was significant $[\mathrm{F}(2,30)=5.4, p<.01]$. Further analyses of this interaction revealed a significant effect of condition in the ASD group $[\mathrm{F}(1,10)=7.6, p<.05]$, showing better performance in the $\operatorname{HSF}(M=3.5, \mathrm{SD}=$ 1.7) than in the LSF condition $(M=5, \mathrm{SD}=2.1$; see Fig. 3). In contrast, the VMA group performed better in the $\operatorname{LSF}(M=3.9, \mathrm{SD}=3.8)$ than in the $\operatorname{HSF}(M=$ $5.8 ; \mathrm{SD}=3.8),(\mathrm{F}(1,10)=6, p<.05$; see Fig. 3$)$. Although not reaching a level of significance, the performance of the CA group also shows more errors in the $\operatorname{HSF}(M=4, \mathrm{SD}=3.8)$ than in the LSF $(M=2.5$, $\mathrm{SD}=2.5)$.

Interestingly, performance of CA or VMA groups did not increase with age, whereas the autistic subjects became better with age (Rho $=.78, p<.05)$; this effect was significant in the LSF (Rho $=.75, p<.05)$ but not in the HSF condition $(p>.05)$.

\section{GENERAL DISCUSSION}

These experiments suggest two main conclusions. First, data from experiment 1 showed that facial identity recognition was not impaired in children with autism. These findings support earlier studies conducted by Hobson et al. (1988) and by Langdell (1978), 
showing that mentally retarded autistic children, adolescents, and adults are proficient in judging faces by identity. Similarly, another study (e.g., Gepner et al., 1996) using the same facial-identity matching procedure as in our study, reported that autistic children performed as well as their controls matched for verbal mental age. The pattern of strengths and weaknesses in the various aspects of face processing evaluated in experiment 1 is not the same between controls and autistic population, indicating the use of different strategies in these populations.

Second, results of the second experiment confirmed that facial identities are recognized in a different way by autistic and Asperger subjects than by normally developing children matched on verbal mental age. Whereas children of the VMA group used primarily LSF information, children with autism based their judgments on HSF cues. Our study is the first demonstration, to our knowledge, of a HSF preference in the autistic population. If mere exposure rather than developmental progression in cognitive skills determined this difference, then these autistic youngsters should show the same pattern as normally developing children. This hypothesis is not confirmed by the data.

As exposed earlier, numerous studies have established a link between LSF and configural processing and between HSF and local processing (e.g., Hughes et al., 1996). Thus, the better results of our control subjects in the LSF than in the HSF condition agrees with the idea that typically developing children (Baenninger, 1994; Carey \& Diamond, 1994; Tanaka et al., 1998), as well as normal adults (e.g., Rhodes, 1988), use configural information in face processing. In contrast, performance of the autistic children indicates that they relied more on local (HSF) than on configural (LSF) cues when processing faces, thus confirming data from previous studies (Hobson et al., 1988; Langdell, 1978; Miyashita, 1988). A recent study by Schultz and colleagues (2000) showed that individuals with ASD did not engage the same cerebral structure (i.e., the fusiform face area) as controls when processing faces but used structures usually accessed in object processing (i.e., right inferior temporal gyrus). According to the authors, the autistic participants processed faces like objects; that is, by using feature-based strategies. Note, however, that the ability of the autistic children to process LSF information seems to benefit from age and practice. It is more plausible that a dysfunction in configural face analysis is observed in children with autism because of their lack of face expertise. This explanation concords with the proposal defended by Grelotti and colleagues (Grelotti, Gauthier, \& Schultz, 2002) that the poor specialization for faces that results from an atypical way of processing faces (more locally than configurally) and the inactivation of the fusiform face area in the autistic population could be the result of their lack of expertise with faces. However, tasks using nonsocial stimuli have also put forward a possible deficit in configural processing in the autistic population (Deruelle et al., submitted).

Further studies including mentally retarded nonautistic children are necessary to make conclusions about the specificity of the pattern of results observed in the autistic group. However, it seems unlikely that we will obtain similar findings on mentally retarded nonautistic children, as earlier studies have revealed different ways of performing visual face-processing tasks in these two populations (e.g., Campbell et al., 1999; Hobson et al., 1988; Langdell, 1978). For instance, studies have established that nonautistic retarded children were less focused on facial features than autistic children when they had to sort faces on the basis of emotional expression or identity (e.g., Hobson et al., 1988).

The local advantage in face processing observed in children with autism and Asperger syndrome is in accordance with the local bias demonstrated in this population in tasks involving object perception (e.g., Mottron, Belleville, \& Ménard, 1999) and with the "weak central coherence" theory defended by Frith (1989). In line with Frith (1989), Happé's (1999) recent review proposed that this weak central coherence may concern perceptual, visuo-spatial, visuo-constructive, and semantic processing. Our results bring additional information to this proposition by showing that the local bias observed in autistic children could be expressed as early in the information processing as spatial frequency decoding.

Though the peculiarities in face recognition observed in our autistic group are not related to developmental level, the possibility that they could originate from brain developmental abnormalities should not be excluded. In particular, a specific impairment of the dorsal visual pathway in the autistic population has been evoked (e.g., Spencer et al., 2000). What could our findings imply in terms of neuro-functional pathways?

In the visual pathway from the retina to the cortex, two functional distinct streams may be distinguished. At the level of the lateral geniculate nucleus, a magnocellular system (containing large cell bodies) codes for movement and contrast and a parvocellular system (containing small cell bodies) codes for color and fine visual texture. Beyond the prestriate cortex, a dorsal and a ventral visual pathway may be identified. The dorsal pathway receives inputs from the magnocellular system, whereas the ventral pathway receives inputs from both the magno- and the parvocellular systems (e.g., Merigan \& Maunsell, 1993). 
Low- and high-spatial frequency processing has been related to the magno-parvo visual pathway. It has been advanced that the magnocellular system shows greater sensitivity to low spatial frequencies (i.e., to those characteristics that correspond to the overall, global/configural properties of a visual stimulus), whereas the parvocellular system shows greater sensitivity to high spatial frequencies (i.e., to those characteristics that correspond to the finer, local details of a visual stimulus) (e.g., Breitmeyer, 1975).

Difference in the maturational speed between the two pathways could partly explain why one pathway would be specifically altered in a developmental syndrome such as autism. However, data on the developmental course of magno- and parvocellular pathway maturations are somehow in contradiction. On one hand, some neuro-anatomical findings have indicated that the parvocellular system reaches maturity earlier than the magnocellular system (see Hickey \& Peduzzi, 1987). On the other hand, various studies showed that newborn humans preferentially process low rather than high spatial frequencies (see de Schonen \& Mathivet, 1989, for a review). Nevertheless, several data have indicated that the magno-pathway is particularly vulnerable in developmental neurological impairments. Specific deficits of the magnocellular pathway in dyslexia have indeed often been reported (e.g., Galaburda, 1993). If the hypothesis is verified that the magnocellular system deficiency is at the origins of the peculiar visual behavior observed in children with autism, then it would indicate that their different style of processing is present very early in life.

Because it is assumed that the magnocellular stream mainly projects to the dorsal pathway (DeYoe \& Van Essen, 1988), our findings are in agreement with recent data indicating a specific deficit in the dorsal pathway in autism (Spencer et al., 2000). These authors showed that autistic children exhibited higher thresholds in motion coherence perception (involving the dorsal pathway) than typically developing children, whereas these differences did not emerge for the formcoherence threshold (involving the ventral pathway). Also consistent with a dorsal pathway impairment in the autistic population are two studies revealing that autistic children are severely impaired in visually perceived environmental motion (Gepner, Mestre, Masson, \& de Schonen, 1995; Gepner \& Mestre, 2002).

Caution is, however, requested when interpreting our results in terms of a dorsal visual system impairment in the autistic population. First of all, the hypothesis of a magno- or a parvocellular deficit was not directly tested in our study. Furthermore, though the dorsal stream receives its projections primarily from the magnocellular pathway, the ventral stream likely receives projections from both the magno- and parvocellular pathways (e.g., Merigan \& Maunsell, 1993). Thus, even though an anomalous development of the magnocellular visual system could be evidenced in autism, it would not directly imply that only the dorsal pathway is impaired in this population. In addition, the hypothesis of a dorsal pathway deficit is supported neither by animal models (for a review, see Bachevalier, 1994) nor by studies using functional neuroimaging in autism (e.g., Boddaert \& Zilbovicius, 2002), which indicate that the medial temporal lobe is an appealing candidate as a neural substrate underlying the social deficits in autism. Furthermore, recent fMRI data revealed that face recognition difficulties in subjects with autism could result from a deficit of the medial temporal lobe (e.g., Dawson, Meltzoff, Osterling, \& Rinaldi, 1998; Howard et al., 2000), though it is upheld by both Schultz and colleagues (2000) and by Pierce, Müller, Ambrose, Allen, and Courchesne (2001), who showed that individuals with autism and Asperger syndrome exhibited abnormal ventral temporal cortical activity during face discrimination. These contradictory results prove that more research on the neuroanatomy and the development of the visual stream in autism is necessary before jumping to conclusions.

Our study, in line with earlier findings (e.g., Minshew, Goldstein, \& Siegel, 1997), emphasizes that neuropsychological functioning in autism should take into consideration intact abilities and deficits. Some aspects of visual perception are good and sometimes even above normal in certain domains (see Happé, 1999, for a review). As shown by the current study, autistic individuals do not attend to the same information within faces as normally developing children. Nevertheless, the use of a different strategy does not preclude good performance in facial identity recognition.

Furthermore, it may be interesting to note that a frequency bias was recently reported in the auditory domain (e.g., Mottron, Peretz, \& Ménard, 2000), indicating that a general mechanism could explain enhanced abilities in the autistic population independent of the modality. Additional studies are, of course, needed to elucidate this issue.

\section{ACKNOWLEDGMENTS}

We are especially indebted to the autistic and typically developing children who participated in this study, as well as to their parents and to the staff of the 
child daycare unit of Montperrin hospital. We wish to thank anonymous reviewers for their helpful comments on the first manuscript.

\section{REFERENCES}

American Psychiatric Association (1994). Diagnostic and Statistical Manual of Mental Disorders (4th ed.). Washington, DC: Author.

Bachevalier, J. (1994). Medial temporal lobe structures and autism: A review of clinical and experimental findings. Neuropsychologia, 32, 627-648.

Baenninger, M. (1994). The development of face recognition: Featural or configurational processing? Journal of Experimental Child Psychology, 57, 377-396.

Baron-Cohen, S., Campbell, R., Karmiloff-Smith, A., \& Grant, J. (1995). Are children with autism blind to the mentalistic significance of the eyes? British Journal of Developmental Psychology, 13, 379-398.

Boddaert, N., \& Zilbovicius, M. (2002). Functional neuroimaging and childhood autism. Pediatric Radiology, 32, 1-7.

Breitmeyer, B. G. (1975). Simple reaction time as a measure of the temporal response properties of transient and sustained channels. Vision Research, 15, 1411-1412.

Breitmeyer, B. G. (1984). Visual masking. New York: Oxford University Press.

Calder, A. J., Young, A., Keane, J., \& Dean, M. (2000). Configural information in facial expression perception. Journal of Experimental Psychology: Human Perception and Performance, 26, $527-551$.

Campbell, R., Coleman, M., Walker, J., Benson, P. J., Wallace, S., Michelotti, J., \& Baron-Cohen, S. (1999). When does the innerface advantage in familiar face recognition arise and why? Visual Cognition, 6, 197-216.

Campbell, R., Landis, T., \& Regard, M. (1986). Face recognition and lipreading. Brain, 109, 509-521.

Carey, S., \& Diamond, R. (1977). From piecemeal to configurational representation of faces. Science, 195, 312-314.

Carey, S., \& Diamond, R. (1994). Are faces perceived as configurations more by adults than by children? Visual Cognition, 1, 253-274.

Celani, G., Battacchi, M. W., \& Arcidiacono, L. (1999). The understanding of the emotional meaning of facial expressions in people with autism. Journal of Autism and Developmental Disorders, 29, 57-66.

Costen, N. P., Parker, D. M., \& Craw, I. (1994). Effects of high-pass and low-pass spatial filtering on face identification. Perception and Psychophysics, 38, 602-612.

Davies, S., Bishop, D., Manstead, A. S. R., \& Tantam, D. (1994). Face perception in children with autism and Asperger's syndrome. Journal of Child Psychology and Psychiatry, 35, 1033-1057.

Dawson, G., Meltzoff, A. N., Osterling, J., \& Rinaldi, J. (1998). Neuropsychological correlates of early symptoms of autism. Child Development, 69, 1276-1285.

Deltour, J. J., \& Hupkens, D. (1980). TVAP, Test de Vocabulaire Actif et Passif. EAP, Editions Scientifiques et Psychologiques, Issy les Moulineaux.

Deruelle, C., \& de Schonen, S. (1998). Do the right and the left hemispheres attend to the same visual information within a face in infancy? Developmental Neuropsychology, 14, 535-554.

Deruelle, C., Mancini, J., Livet, M. O., Cassé Perrot, C., \& de Schonen, S. (1999). Configural and local processing of faces in children with Williams syndrome. Brain and Cognition, 41, 276-298.
Deruelle, C., Rondan, C., Gepner, B., Wicker, B., \& Fagot, J. (submitted). Global and configural shape processing in children with autism.

de Gelder, B., Vroomen, J., \& Van der Heide, L. (1991). Face recognition and lip reading in autism. European Journal of Cognitive Psychology, 3, 69-86.

de Schonen, S., \& Mathivet, E. (1989). First come, first served: A scenario about the development of hemispheric specialization in face recognition during infancy. European Bulletin of Cog nitive Psychology, 9, 3-44.

DeYoe, E. A., \& Van Essen, D. C. (1988). Concurrent processing streams in monkey visual cortex. Trends in Neurosciences, 11, 219-226.

Fein, D., Lucci, D., Braverman, M., \& Waterhouse, L. (1992). Comprehension of affect in context in children with pervasive development disorders. Journal of Child Psychology and Psychiatry, 25, 198-212.

Fiorentini, A., Maffei, L., \& Sandini, G. (1983). The role of higher spatial frequencies in face perception. Perception, 12, 195-201.

Frick, J. E., Colombo, J., \& Ryther Allen, J. (2000). Temporal sequence of global-local processing in 3-month-old infants. Infancy, 1, 375-386.

Frith, U. (1989). Autism: Explaining the enigma. Oxford: Blackwell Science.

Galaburda, A. (1993). Neuroanatomic basis of developmental dyslexia. Neurologic Clinics, 11, 161-173.

Gepner, B., de Gelder, B., \& de Schonen, S. (1996). Face processing in autistics: Evidence for a generalized deficit? Child Neuropsychology, 2, 123-139.

Gepner, B., \& Mestre, D. (2002). Postural reactivity to fast visual motion differentiates autistic from Asperger syndrome children. Journal of Autism and Developmental Disorders, 32, 231-238.

Gepner, B., Mestre, D., Masson, G., \& de Schonen, S. (1995). Postural effects of motion vision in young autistic children. NeuroReport, 6, 1211-1214.

Grelotti, D. J., Gauthier, I., \& Schultz, R. T. (2002). Social interest and the development of cortical face specialization: What autism teaches us about face processing. Developmental Psychobiology, 40, 213-225

Happé, F. (1996). Studying weak central coherence at low levels: Children with autism do not succumb to visual illusions; a research note. Journal of Child Psychology and Psychiatry, 37, 873-877.

Happé, F. (1999). Autism: Cognitive deficit or cognitive style? Trends in Cognitive Science, 3, 216-222.

Hickey, T. L., \& Peduzzi, J. D. (1987). Structure and development of the visual system. In P. Salapatek \& P. Cohen (Eds.), Handbook of infant perception: From sensation to perception. Orlando, FL: Academic Press.

Hill, H., Schyns, P. G., \& Akamatsu, S. (1997). Information and viewpoint dependence in face recognition. Cognition, 62, 201-222.

Hobson, R. P., Ouston, J., \& Lee, A. (1988). What's in a face? The case of autism. British Journal of Psychology, 79, 441-453.

Howard, M. A., Cowell, P. E., Boucher, J., Brocks, P., Mayes, A., Farrant, A., \& Roberts, N. (2000). Convergent neuroanatomical and behavioral evidence of amygdala hypothesis of autism. NeuroReport, 11, 2931-2935.

Hughes, H. C., Nozawa, G., \& Kitterle, F. (1996). Global precedence, spatial frequency channels, and the statistics of natural images. Journal of Cognitive Neuroscience, 8, 197-230.

Kracke, I. (1994). Developmental prosopagnosia in Asperger syndrome: Presentation and discussion of an individual case. Developmental Medicine and Child Neurology, 36, 873-886.

Lamb, M. R., \& Yund, E. W. (1993). The role of spatial frequency in the processing of hierarchically organized stimuli. Perception and Psychophysics, 54, 773-784.

Langdell, T. (1978). Recognition of faces: An approach to the study of autism. Journal of Child Psychology and Psychiatry, 19, $255-268$. 
Lundy, B. L. (2000). Face recognition performance in one-year-olds: A function of stimulus characteristics? Infant Behavior and Development, 23, 125-135.

Merigan, W. H., \& Maunsell, J. H. R. (1993). How parallel are the primate visual pathways? Annual Review of Neuroscience, 16, 369-402.

Minshew, N. J., Goldstein, G., \& Siegel, D. J. (1997). Neuropsychologic functioning in autism: Profile of a complex information processing disorder. Journal of International Neuropsychology Society, 3, 303-316.

Miyashita, T. (1988). Discimination of facial components in autistic children. The Japanese Journal of Psychology, 59, 206-212.

Mottron, L., Belleville, S., \& Ménard, E. (1999). Local bias in autistic subjects as evidenced by graphic perceptual hierarchization or working memory deficit? Journal of Child Psychology and Psychiatry, 40, 743-755.

Mottron, L., Peretz, I., \& Ménard, E. (2000). Local and global processing of music in high-functioning persons with autism Beyond Central Coherence? Journal of Child Psychology and Psychiatry, 41, 1057-1165.

Navon, D. (1977). Forest before trees: The precedence of global features in visual perception. Cognitive Psychology, 9, 353-383.

Pierce, K., Müller, R. A., Ambrose, J., Allen, G., \& Courchesne, E. (2001). Face processing occurs outside the fusiform "face area" in autism: Evidence from functional MRI. Brain, 124, 2059-2073.

Ricciardelli, P., Ro, T., \& Driver, J. (2002). A left visual field advantage in perception of gaze direction. Neuropsychologia, 40, 769-777.

Rhodes, G. (1988). Looking at faces: First-order and second order features as determinants of facial appearance. Perception, 17, 43-63.

Schopler, E., Reichler, R. J., DeVellis, R. F., \& Daly, K. (1980). Toward objective classification of childhood autism: Childhood autism rating scale (CARS). Journal of Autism and Developmental Disorders, 10, 91-103.

Schultz, R. T., Gauthier, I., Klin, A., Fulbright, R. K., Anderson, A. W., Volkmar, F., Skudlarski, P., Lacadie, C., Cohen, D. J., \& Gore, J. C. (2000). Abnormal ventral temporal cortical activity during face discrimination among individuals with autism and Asperger syndrome. Archives of General Psychiatry, 37, $331-340$.

Schyns, P. G., \& Oliva, A. (1999). Dr Angry and Mr Smile: When categorization flexibly modifies the perception of faces in rapid visual presentations. Cognition, 69, 243-265.

Sergent, J. (1982). The cerebral balance of power: Confrontation or cooperation? Journal of Experimental Psychology: Human Perception Performance, 8, 253-272.

Sergent, J. (1986). Microgenesis in face perception. In H. D. Ellis, M. A. Jeeves, F. Newcombe, \& A. Young (Eds.), Aspects of face processing (pp. 17-73). Dordrecht: Martinus Nijhoff.

Shah, A., \& Frith, U. (1983). An islet of ability in autistic children: A research note. Journal of Child Psychology and Psychiatry, $24,613-620$

Shah, A., \& Frith, U. (1993). Why do autistic individuals show superior performance on the block design task? Journal of Child Psychology and Psychiatry, 34, 1351-1364.

Shulman, G. L., \& Wilson, J. (1987). Spatial frequency and selective attention to local and global information. Perception, 16, 89-101.

Spencer, J., O’Brien, J., Riggs, K., Braddick, O., Atkinson, J., \& Wattam-Bell, J. (2000). Motion processing in autism: Evidence of a dorsal stream deficiency. Neuroreport, 11, 2765-2767.

Tanaka, J. W., \& Farah, M. J. (1993). Parts and wholes in face recognition. Quaterly Journal of Experimental Psychology, 46a, $225-245$.

Tanaka, J. W., Kay, J. B., Grinnell, E., Stansfield, B., \& Szechter, L. (1998). Face recognition in young children: When the whole is greater than the sum of its parts. Visual Cognition, 5, 479-496.

Tantam, D., Monaghan, L., Nicholson, H., \& Stirling, J. (1989). Autistic children's ability to interpret faces: A research note. Journal of Child Psychology and Psychiatry, 30, 623-630.

Yamaguchi, M. K., Hirukawa, T., \& Kanazawa, S. (1995). Judgment of gender through facial parts. Perception, 24, 563-575.

Young, A. W., Hellawell, D., \& Hay, D. C. (1987). Configural information in face perception. Perception, 16, 747-759. 